\title{
Effect of continuous positive airway pressure therapy on inflammatory cytokines and atherosclerosis in patients with obstructive sleep apnea syndrome
}

\author{
FA JIN $^{1 *}$, JIANNAN LIU ${ }^{2 *}$, XIUWEI ZHANG ${ }^{1}$, WEI CAI $^{1}$, YUQIONG ZHANG $^{3}$, \\ WEI ZHANG ${ }^{1}$, JIAN YANG ${ }^{1}$, GAN LU $^{2}$ and XILONG ZHANG ${ }^{4}$ \\ ${ }^{1}$ Department of Respiration, The Affiliated Jiangning Hospital of Nanjing Medical University; \\ ${ }^{2}$ Department of Respiratory, Jiangsu Province Official Hospital; ${ }^{3}$ Department of Cardiology, \\ The Affiliated Jiangning Hospital of Nanjing Medical University, Nanjing, Jiangsu 211100; \\ ${ }^{4}$ Department of Respiratory, Jiangsu Province Hospital, Nanjing, Jiangsu 210029, P.R. China
}

Received May 4, 2016; Accepted March 28, 2017

DOI: $10.3892 / \mathrm{mmr} .2017 .7399$

\begin{abstract}
Obstructive sleep apnea syndrome (OSAS) is known to be a risk factor for atherosclerosis (AS), derived from a series of chronic inflammatory reactions caused by hypoxia. However, the association between chronic inflammation and high blood pressure caused by hypoxia remains to be fully elucidated. The aim of the present study was to investigate the effect of continuous positive airway pressure (CPAP) therapy on inflammatory cytokines and AS. A total of 100 patients with OSAS and 50 healthy control subjects were enrolled. Fresh venous blood samples were collected prior to and following a 3-months period of CPAP treatment. The inflammatory factors, interleukin (IL)-18 and tumor necrosis factor (TNF)- $\alpha, \mathrm{C}$-reactive protein (CRP), intercellular cell adhesion molecule 1 (ICAM-1), vascular cell adhesion molecule 1 (VCAM-1), E-selectin and P-selectin, were detected using standard enzyme-linked immunosorbent assay kits. Intima-media thickness (IMT), brachial-ankle pulse wave velocity (Ba-PWV), apnea-hypopnea index (AHI) and transcutaneous oxygen saturation $\left(\mathrm{SpO}_{2}\right)$ were also detected to compare differences prior to and following treatment. The results showed that, compared with the pre-treatment data, the expression levels of IL-8, TNF- $\alpha$, CRP, ICAM-1, VCAM-1, E-selectin and P-selectin were significantly decreased following treatment $(\mathrm{P}<0.05)$. The AHI, IMT, blood pressure
\end{abstract}

Correspondence to: Dr Jian Yang, Department of Respiration, The Affiliated Jiangning Hospital of Nanjing Medical University, 168 Gushan Road, Nanjing, Jiangsu 211100, P.R. China

E-mail: yangjian_2016@sina.com

${ }^{*}$ Contributed equally

Key words: obstructive sleep apnea syndrome, atherosclerosis, continuous positive airway pressure, intima-media thickness, brachial-ankle pulse wave velocity, apnea hypopnea index and Ba-PWV values were significantly decreased $(\mathrm{P}<0.05)$, and the $\mathrm{SpO}_{2}$ was increased $(\mathrm{P}<0.05)$. Taken together, by comparing the pre- and post-intervention data, it was confirmed that inflammatory factors were involved in the process of AS in patients with OSAS. Following CPAP treatment, blood pressure and primary indicators in the patients improved.

\section{Introduction}

Obstructive sleep apnea syndrome (OSAS), which affects 2-4\% of the population worldwide, is a common sleep disorder and potential clinical risk factor. OSAS has been widely considered as a severe problem associated with a range of pathological consequences, including hypoxia (1), hypercapnia (2), imbalance of nerve regulation function (3), activation of the rennin angiotensin aldosterone system, catecholamine and endothelin secretion, endocrine dysfunction and hemodynamic changes (4). Of all the problems reported in patients with OSAS, the most important consequence is the risk of cardiovascular and cerebrovascular disease (5). OSAS has long been confirmed as one of the most important independent risk factors for atherosclerosis (AS) and hypertension (6). Tissue hypoxia followed by chronic inflammation damage and the involvement of a variety of inflammatory cytokines leads to AS (7).

Continuous positive airway pressure (CPAP) therapy is the most effective method for OSAS (8). Adequate CPAP treatment can increase pulmonary ventilation and ameliorate the inflammation of arteries in patients with OSAS (9). Patients show improvements in blood oxygen concentration on the first day following CPAP treatment, and further benefits are observed during an extended course of treatment (10). The molecular and immunological mechanisms underlying this type of therapy are a major concern when selecting CPAP in patients with OSAS.

According to clinical observations and previous investigations, the present study hypothesized that, in patients with OSAS without clinical interventions, the plasma levels of interleukin (IL)-18, tumor necrosis factor (TNF)- $\alpha$ (11), C-reactive protein 
(CRP), intercellular cell adhesion molecule 1 (ICAM-1), vascular cell adhesion molecule 1 (VCAM-1), E-selectin and P-selectin are significantly altered. The present study investigated these factors and compared changes following CPAP (12). On the basis of these observations, alterations in the clinical characteristics of OSAS following treatment were observed. In order to evaluate the effect of CPAP (5) on inflammatory factors and AS, the present study also examined the carotid intima-media thickness (IMT) and brachial-ankle pulse wave velocity (Ba-PWV) (13). The aim of the present study was to evaluate the effects of a longer (3-month) period of CPAP treatment on oxygen ventilation in patients with OSAS.

\section{Subjects and methods}

Subjects and healthy donors. In the present study, a total of 100 patients were recruited from The Affiliated Jiangning Hospital of Nanjing Medical University (Nanjing, China) upon diagnosis on interpretation of clinical guidelines on the treatment of OSAS (American College of Physicians, 2013) (14). The patients included 82 men and 18 women, aged between 43 and 69 years old (mean age, 55.28 7.12 years). These patients were prospectively recruited on preparing to attend the Sleep Clinic for overnight polysomnography (PSG) between March 2014 and March 2016, who met the standard definition of an apnea-hypopnea index (AHI) $\geq 5$. None of the patients were suffering from serious disease requiring treatment. As a healthy control group, 50 individuals undergoing physical examination at The Affiliated Jiangning Hospital of Nanjing Medical University were invited to join in this study sequence. There were no differences in age, gender or body mass index (BMI) between the healthy control group and the OSAS group.

The exclusion criteria included patients or healthy donors with coronary heart disease, valvular heart disease, cardiomyopathy, tumors, severe liver and kidney dysfunction, severe lung disease, hyperlipidemia, diabetes, hypertension, infection or trauma, or had undergone surgery in the previous 2 weeks. The present study was approved by the Ethics Committee of The Affiliated Jiangning Hospital of Nanjing Medical University. Written informed consent was obtained from each patient and healthy donor.

Specimen collection and detection of inflammatory factors. Blood samples were collected from the study subjects in the early morning (6:00 a.m.). Fasting blood was collected again from the patients with OSAS following CPAP treatment for 3 months (again at 6:00 a.m.). All blood samples were $10 \mathrm{ml}$ in volume and obtained from the elbow vein. The samples underwent $300 \mathrm{x}$ g centrifugation at $10^{\circ} \mathrm{C}$ for $10 \mathrm{~min}$, and the upper plasma was stored at $-80^{\circ} \mathrm{C}$. IL-18 and TNF- $\alpha, \mathrm{CRP}$, ICAM-1, VCAM-1, E-selectin and P-selectin were detected using an enzyme-linked immunosorbent assay (ELISA). The concentrations of the inflammatory factors were measured using human ELISA kits (Amersham; GE Healthcare Life Sciences, Chalfont, UK).

CPAP treatment. The recording and comparing of sleep monitoring parameters during the 3-month treatment period were performed using a compumedics PSG monitoring system
(ResMed, Sydney, Australia). The AHI and transcutaneous oxygen saturation $\left(\mathrm{SpO}_{2}\right)$ were detected and recorded prior to and following the 3-month treatment period.

Ultrasound measurement of carotid IMT. The carotid artery IMT was detected using the Mylab 90 ultrasonic instrument (Esaote, Genoa, Italy) as the quality of IMT.

Detection of $\mathrm{Ba}-\mathrm{PWV}$. The Ba-PWV was detected using an automatic AS testing equipment (BP-203RPEII; Omron Colin, Tokyo, Japan).

The upper arm to the ankle propagation distance (L) and the pulse wave transit time ( $\mathrm{T}$ ) were automatically measured according to the height of the body. The formula Ba-PWV=L/T was calculated from Ba-Pwv on both sides, and the average value of both sides was recorded.

Statistical analysis. The statistical analyses performed included a matched t-test of measurement data and a rank-sum test using SPSS 16.0 software (SPSS, Inc., Chicago, IL, USA). All data are presented as the mean \pm standard deviation. $\mathrm{P}<0.05$ was considered to indicate a statistically significant difference.

\section{Results}

General characteristics of study subjects. All 100 patients and 50 healthy controls were included in the study. Table I lists the characteristics of the subjects. No differences in gender, age or BMI were found between the two groups $(\mathrm{P}>0.05)$. The baseline clinical data of the subjects are also listed in Table I.

Inflammatory factors in OSAS. Compared with the healthy control group, the expression levels of IL-8, TNF- $\alpha$, CRP, ICAM-1, VCAM-1, E-selectin and P-selectin in the patients with OSAS were significantly increased. The respective statistical comparisons of expression in the healthy controls, vs. patients with OSAS were as follows: IL-8, $13.28 \pm 3.15$, vs. $40.72 \pm 1.60 \mathrm{pg} / \mathrm{ml}(\mathrm{P}=0.0013) ; \mathrm{TNF}-\alpha$, 29.15 \pm 1.74 , vs. $37.67 \pm 0.21 \mathrm{pg} / \mathrm{ml}(\mathrm{P}=0.0037)$; $\mathrm{CRP}, 6.37 \pm 1.30$, vs. $49.64 \pm 21.66 \mathrm{mg} / \mathrm{l}(\mathrm{P}=0.0007)$; ICAM-1, 291.68 \pm 53.29 , vs. $357.92 \pm 10.52 \mu \mathrm{g} / \mathrm{l}(\mathrm{P}=0.0170)$; VCAM-1, 288.16 \pm 48.81 , vs. $351.06 \pm 53.61 \mu \mathrm{g} / \mathrm{l}(\mathrm{P}=0.0201)$; E-selectin, $42.57 \pm 10.4$, vs. $50.65 \pm 8.29 \mu \mathrm{g} / \mathrm{l}(\mathrm{P}=0.0233)$; $\mathrm{P}$-selectin $30.26 \pm 6.80$ and $54.79 \pm 3.34 \mu \mathrm{g} / \mathrm{l}(\mathrm{P}=0.0149)$. The results are shown in Fig. 1 .

Changes of inflammatory cytokines following treatment. PSG was performed on patients treated with CPAP using an automatically programmed PSG system following 3 months of treatment. Compared with the pre-therapy data, the expression levels of IL-8, TNF- $\alpha$, CRP, ICAM-1, VCAM-1, E-selectin and P-selectin were significantly decreased following treatment. The statistical comparisons of post-treatment, vs. pre-treatment data were as follows: IL-8, 35.79 \pm 1.63 and 40.72 $\pm 1.60 \mathrm{pg} / \mathrm{ml}(\mathrm{P}=0.0392)$; TNF- $\alpha$, $34.97 \pm 3.18$ vs. $37.67 \pm 0.21 \mathrm{pg} / \mathrm{ml}(\mathrm{P}=0.0412)$; $\mathrm{CRP}, 27.41 \pm 8.86$ vs. $49.64 \pm 21.66 \mathrm{mg} / \mathrm{l}(\mathrm{P}=0.0138) ; \mathrm{ICAM}-1,338.29 \pm 43.03$ vs. $357.92 \pm 10.52 \mu \mathrm{g} / 1(\mathrm{P}=0.0219)$; VCAM-1, 322.36 \pm 38.25 vs. $351.06 \pm 53.61 \mu \mathrm{g} / \mathrm{l}(\mathrm{P}=0.0015)$; E-selectin, 47.46 \pm 8.58 vs. $50.65 \pm 8.29 \mu \mathrm{g} / 1 \quad(\mathrm{P}=0.0143)$; $\mathrm{P}$-selectin, 44.05 \pm 6.97 vs. 54.79 $\pm 3.34 \mu \mathrm{g} / \mathrm{l}(\mathrm{P}=0.0019)$. The results are shown in Fig. 2 . 
Table I. General characteristics of the study participants.

\begin{tabular}{lccc}
\hline Variable & OSAS & Healthy control & P-value \\
\hline Number & 100 & 50 & ND \\
Male/female & $82 / 18$ & $37 / 13$ & 0.288 \\
Age $($ years $)$ & $55.284 \pm 7.128$ & $56.131 \pm 6.210$ & 0.193 \\
$\mathrm{BMI}\left(\mathrm{kg} / \mathrm{m}^{2}\right)$ & $26.746 \pm 3.500$ & $25.196 \pm 2.449$ & 0.528 \\
$\mathrm{SBP}(\mathrm{mmHg})$ & $162.549 \pm 7.315$ & $128.124 \pm 8.341$ & 0.021 \\
$\mathrm{DBP}(\mathrm{mmHg})$ & $95.328 \pm 5.515$ & $83.425 \pm 4.216$ & 0.007 \\
$\mathrm{TC}(\mathrm{mmol} / \mathrm{l})$ & $6.718 \pm 2.998$ & $4.624 \pm 2.378$ & 0.022 \\
$\mathrm{AHI}(/ \mathrm{h})$ & $38.011 \pm 8.040$ & $3.623 \pm 1.537$ & 0.001 \\
SPO $(\%)$ & $89.183 \pm 7.234$ & $95.271 \pm 2.490$ & 0.018 \\
Hypertension duration (years) & $6.227 \pm 2.887$ & $\mathrm{ND}$ & $\mathrm{ND}$ \\
Classes of hypotensor used (no.) & $2.6 \pm 0.4$ & $\mathrm{ND}$ & $\mathrm{ND}$
\end{tabular}

OSAS, obstructive sleep apnea syndrome; BMI, body mass index; SBP, systolic blood pressure; DBP, diastolic blood pressure; TC, total cholesterol; $\mathrm{AHI}$, apnea hypopnea index; $\mathrm{SPO}_{2}$, pulse oxygen saturation; $\mathrm{ND}$, no data.

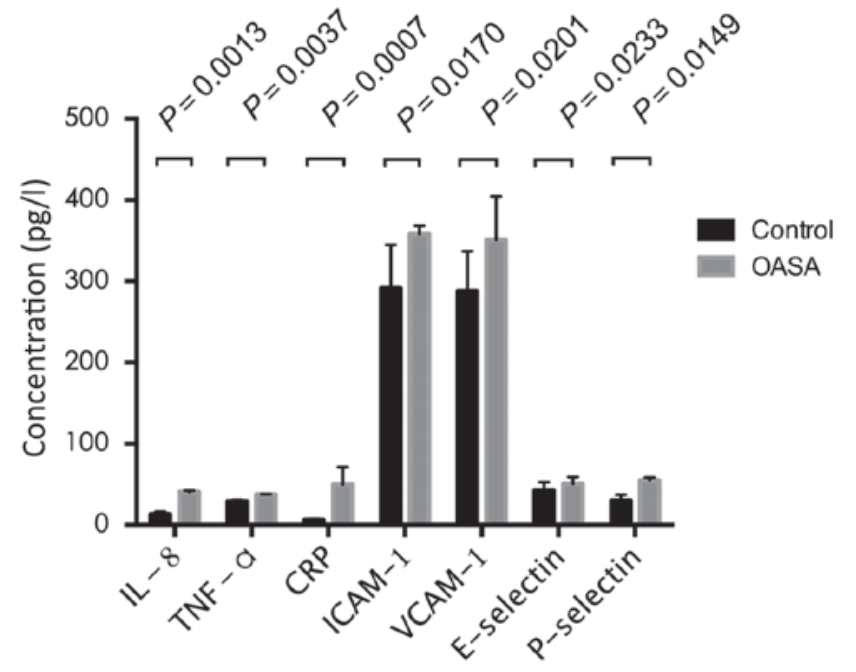

Figure 1. Inflammatory factors in OSAS. IL-18, interleukin-18; TNF- $\alpha$, tumor necrosis factor- $\alpha$; CRP, C-reactive protein; ICAM-1, intercellular cell adhesion molecule 1; VCAM-1, vascular cell adhesion molecule 1; OSAS, obstructive sleep apnea syndrome.

$A H I$ and $B a-P w v$. Following CPAP treatment, the AHI and Ba-Pwv improved significantly. As shown in Fig. 3A, the average value of AHI decreased significantly (37.80 \pm 6.70 vs. $26.73 \pm 4.34 ; \mathrm{P}=0.0019)$, as did that of $\mathrm{Ba}-\mathrm{Pwv}$ $(1,418.86 \pm 199.58$ vs. $1,265.31 \pm 219.36 ; P=0.0239$; Fig. $3 B)$.

IMT and $\mathrm{SPO}_{2}$. Compared with pre-treatment, the IMT following treatment was significantly reduced $(1.35 \pm 0.55$ vs. $1.12 \pm 0.52$, respectively; $\mathrm{P}=0.0381$ ), whereas $\mathrm{SPO}_{2}$ was significantly increased $(81.67 \pm 7.23$ vs. $89.18 \pm 5.19$, respectively; $\mathrm{P}=0.0283$ ), as shown in Fig. $4 \mathrm{~A}$ and $\mathrm{B}$.

SBP and DBP. In the patients whose blood pressure remained high despite medication $(n=78)$, the blood pressure was improved following treatment. As is shown in Fig. 5A and B, the decreases in SBP $(168.84 \pm 32.57$ vs. $144.29 \pm 17.85$;

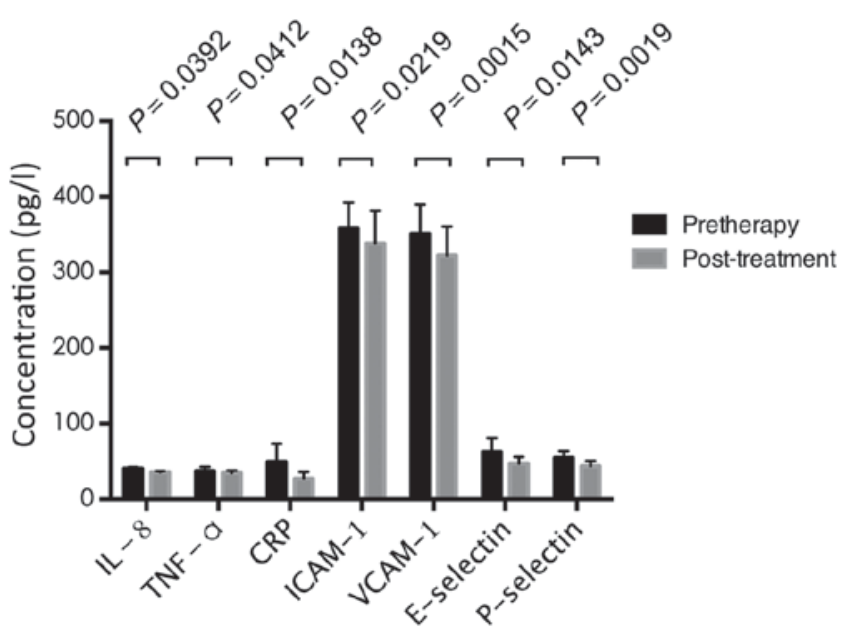

Figure 2. Changes in inflammatory cytokines following treatment. IL-18, interleukin-18; TNF- $\alpha$, tumor necrosis factor- $\alpha$; CRP, C-reactive protein; ICAM-1, intercellular cell adhesion molecule 1; VCAM-1, vascular cell adhesion molecule 1 .

$\mathrm{P}=0.0013)$ and DBP $(84.21 \pm 11.85$ vs. $79.47 \pm 8.98 ; \mathrm{P}=0.0021)$ were statistically significant.

\section{Discussion}

In previous years, OSAS has been widely accepted as a mechanism for hypertension, and specific treatment for this change has also been considered. In the present study, CAPA was used for the treatment of patients with OSAS and hypertension, and the efficacy was observed in order to examine the novel treatment approach for patients with OSAS and hypertension.

The pro-inflammatory cytokine IL-18 is important in the occurrence and development of atherosclerotic plaque rupture (15). An epidemiological follow-up study revealed that IL-18 is an independent risk factor for coronary events, and is also a predictor of life-threatening cardiac events in patients with acute coronary syndrome (10). TNF- $\alpha$ is critical in the 
A

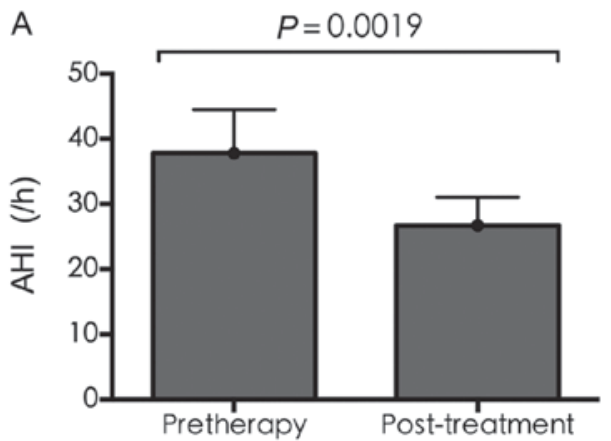

B

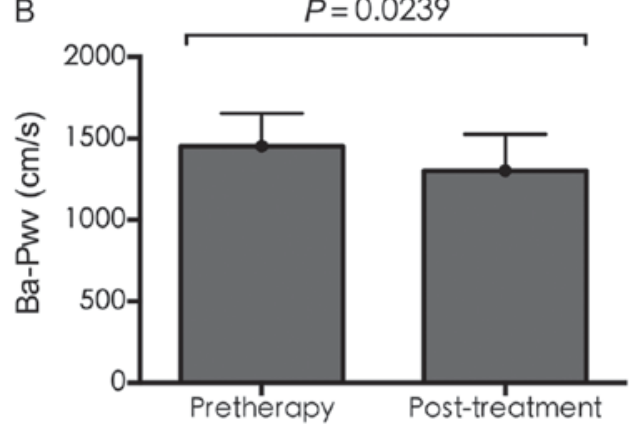

Figure 3. Changes in AHI and Ba-PWV following continuous positive airway pressure treatment. (A) Analysis of AHI following treatment. (B) Statistical analysis of Ba-PWV following treatment. AHI, apnea hypopnea; Ba-PWV, brachial-ankle pulse wave velocity.
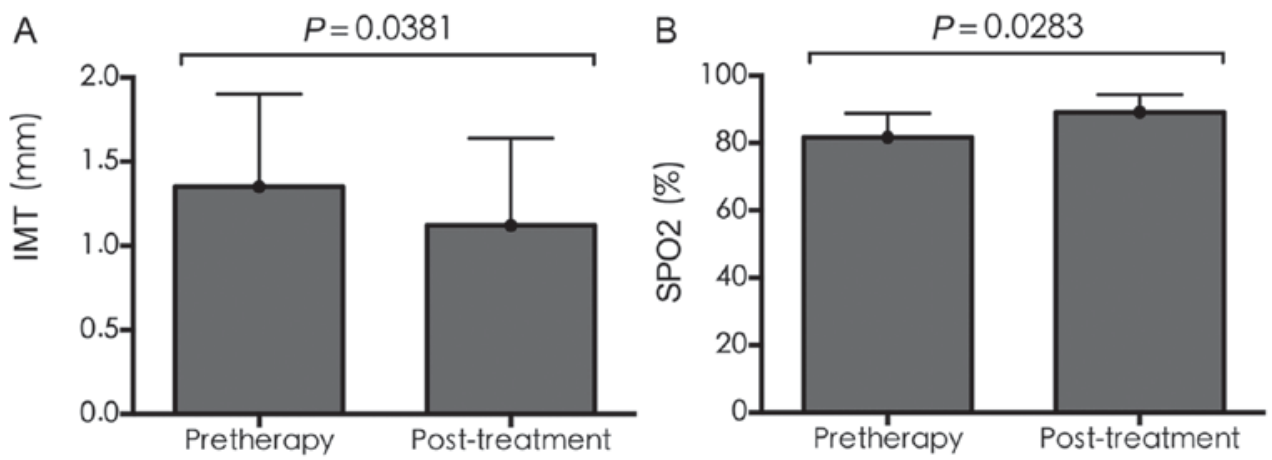

Figure 4. Changes in IMT and $\mathrm{SPO}_{2}$ following continuous positive airway pressure treatment. (A) Analysis of IMT following treatment. (B) Analysis of $\mathrm{SPO}_{2}$ following treatment. IMT, intima-media thickness; $\mathrm{SPO}_{2}$, pulse oxygen saturation.
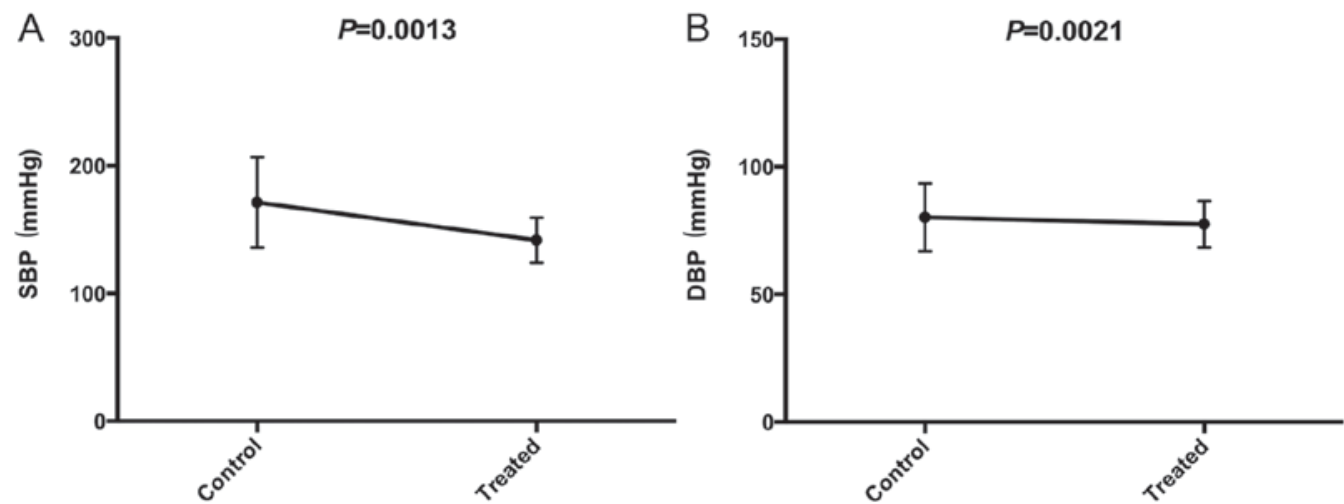

Figure 5. Changes in blood pressure following continuous positive airway pressure treatment. Changes in (A) DBP and (B) SBP following treatment. DBP, diastolic blood pressure; SBP, systolic blood pressure.

inflammatory cascade reaction of AS. Although CRP cannot predict disease specificity, it is an important inflammatory response factor in the majority of types of chronic inflammation, particularly in AS. In addition, inflammatory factors, including ICAM-1, VCAM-1 (16), E-selectin and P-selectin, have been found to be important in predicting the occurrence and development of AS (17). The pathological basis of AS involves chronic inflammation of the vascular wall (18), however, whether inflammation is also involved in the pathogenesis of cardiovascular disease in patients with OSAS remains to be fully elucidated. The present study hypothesized that hypoxia causes chronic inflammation in patients with
OSAS, and chronic inflammation leads to AS and hypertension, whereas mechanical ventilation improves the condition of hypoxia and the inflammatory response in patients.

The results of the present study showed that IL-18, TNF- $\alpha$, high-sensitivity CRP, and serum levels of ICAM-1, VCAM-1, E-selectin and P-selectin in the OSAS group were significantly increased, compared with those in the healthy control group. It was indirectly confirmed that these inflammatory factors may be involved in hypoxia and in vascular sclerosis. In order to directly confirm this mechanism, CPAP treatment and follow-up investigations were performed on patients with OSAS. Following CPAP treatment, significant differences 
were found in these inflammatory markers, compared with those at the pre-treatment stage.

In patients with OSAS with significant characteristics of upper airway collapse (19) and effects on the circulatory system, the primary mechanism involves the excitement of sympathetic nerves (3), increase of endothelin levels (20), vascular endothelial function, abnormalities in vascular active substances (21), vascular tension (22) and excessive renin secretion causing sustained hypertension (23). In previous studies, plasma levels of CRP and other inflammatory cytokines in patients with OSAS caused by inflammation have been reported to promote cardiovascular and cerebrovascular diseases (24), including AS. The overexpression of IL-18, TNF- $\alpha$, E-selectin and P-selectin in OSAS is an important factor in the occurrence and development of hypertension (25).

It has been reported that OSAS is closely associated with the occurrence and development of hypertension (22). Under the condition of low oxygen, substantial cellular metabolic waste accumulation leads to the generation of oxygen free radicals (26). Free radicals react with the unsaturated fatty acids in cells (27), in a process called lipid peroxidation, generating cytotoxic effects of peroxide (28). Oxyradicals and subsequent lipid peroxidation lead to various types of damage in the body. In the electron transport chain of the redox reaction, coenzyme Q in complex III can produce high activity free radical intermediates in the process of reduction (29). The reactive oxygen species generated in these cells include hypochlorite, hydrogen peroxide, and free radicals, including superoxide anions and hydroxyl radicals (30). The chemical properties of hydroxyl radical are unstable and can be divided into specific biological molecules. These biological macromolecules are predominantly produced by the catalytic reduction of hydrogen peroxide by metal enzymes. The oxidant can trigger a chain reaction, for example, lipid peroxidation or oxidation of DNA and protein, resulting in cell damage. Damaged DNA can cause mutations and induce several diseases if not repaired. The damage causes the degradation of protein and inhibits the activity of the enzyme. CPAP can improve patient ventilation status, and subsequently improve in the long-term chronic hypoxia status, with reductions in the redox reaction and generation of free radicals (31).

In the present study, in addition to the changes of inflammatory factors and clinical indices of the patients, AHI, IMT, Ba-Pwv (32) and blood pressure were detected. Patients with OSAS and hypertension exhibited significantly higher IMT and $\mathrm{Ba}-\mathrm{Pwv}$, compared with the normal population. Following treatment of the patients with OSAS, blood pressure (SBP and DBP) and $\mathrm{PSO}_{2}$ was decreased. This showed that CAPA alleviated the changes in OSAS patients with hypertension.

In conclusion, CPAP increases oxygen supply, improves chronic inflammation in OSAS, and inhibits the expression of inflammatory factors and other factors promoting cardiovascular and cerebrovascular diseases, in addition significantly improving to pulmonary function in patients (33). In the present study, it was confirmed that CPAP inhibited the inflammatory response of patients with OSAS and hypertension, and inhibited the pathological basis of OSAS. Therefore, the patients with OSAS exhibited hypertension and hypoxia, leading to inflammation. CPAP indirectly improved AS and high blood pressure in the patients. However, due to the complexity of clinical investigation and confounding factors, there are still some deficiencies in the present study. More cases and longer follow-up are needed to investigate the association between OSAS, chronic inflammation and hypertension.

\section{References}

1. Ulrich S, Nussbaumer-Ochsner Y, Vasic I, Hasler E, Latshang TD, Kohler M, Muehlemann T, Wolf M and Bloch KE: Cerebral oxygenation in patients with OSA: Effects of hypoxia at altitude and impact of acetazolamide. Chest 146: 299-308, 2014.

2. Hollier CA, Harmer AR, Maxwell LJ, Menadue C, Willson GN, Unger G, Flunt D, Black DA and Piper AJ: Moderate concentrations of supplemental oxygen worsen hypercapnia in obesity hypoventilation syndrome: A randomised crossover study. Thorax 69: 346-353, 2014.

3. Yamaguchi K, Inoue Y, Ohki N, Satoya N, Inoue F, Maeda Y, Sekiguchi H, Suzuki M, Tsuji T, Aoshiba K and Nagai A: Gender-specific impacts of apnea, age, and BMI on parasympathetic nerve dysfunction during sleep in patients with obstructive sleep apnea. PLoS One 9: e92808, 2014.

4. Cha J, Zea-Hernandez JA, Sin S, Graw-Panzer K, Shifteh K, Isasi CR, Wagshul ME, Moran EE, Posner J, Zimmerman ME and Arens R: The effects of obstructive sleep apnea syndrome on the dentate gyrus and learning and memory in children. J Neurosci 37: 4280-4288, 2017.

5. Dal-Fabbro C, Garbuio S, D'Almeida V, Cintra FD, Tufik S and Bittencourt L: Mandibular advancement device and CPAP upon cardiovascular parameters in OSA. Sleep Breath 18: 749-759, 2014.

6. Marin JM, Artal J, Martin T, Carrizo SJ, Andres M, Martin-Burriel I, Bolea R, Sanz A, Varona L, Godino J, et al: Epigenetics modifications and subclinical atherosclerosis in obstructive sleep apnea: The EPIOSA study. BMC Pulm Med 14: 114, 2014.

7. Mutlu M, Vuralkan E, Yardim Akaydin S, Akin I and Miser E: Effects of adenoid/tonsillectomy on inflammatory response in snoring children with witnessed apnoea. Clin Otolaryngol 39: 266-271, 2014.

8. Parra O, Sánchez-Armengol Á, Capote F, Bonnin M, Arboix A, Campos-Rodríguez F, Pérez-Ronchel J, Durán-Cantolla J, Martínez-Null C, de la Peña M, et al: Efficacy of continuous positive airway pressure treatment on 5-year survival in patients with ischaemic stroke and obstructive sleep apnea: A randomized controlled trial. J Sleep Res 24: 47-53, 2015.

9. Batool-Anwar S, Goodwin JL, Drescher AA, Baldwin CM, Simon RD, Smith TW and Quan SF: Impact of CPAP on activity patterns and diet in patients with obstructive sleep apnea (OSA). J Clin Sleep Med 10: 465-472, 2014.

10. Shahid ML, Chitiboi T, Ivanovska T, Molchanov V, Völzke H and Linsen L: Automatic MRI segmentation of para-pharyngeal fat pads using interactive visual feature space analysis for classification. BMC Med Imaging 17: 15, 2017.

11. Augelli DM and Krieger AC: Social and economic impacts of managing sleep hypoventilation syndromes. Sleep Med Clin 12: 87-98, 2017.

12. Lin CC, Liaw SF, Chiu CH, Chen WJ, Lin MW and Chang FT: Effects of nasal CPAP on exhaled SIRT1 and tumor necrosis factor- $\alpha$ in patients with obstructive sleep apnea. Respir Physiol Neurobiol 228: 39-46, 2016.

13. Yilmaz YF, Kum RO, Ozcan M, Gungor V and Unal A: Drug-induced sleep endoscopy versus Muller maneuver in patients with retropalatal. Laryngoscope 125: 2220-2225, 2015.

14. Hui DS, Shang Q, Ko FW, Ng SS, Szeto CC, Ngai J, Tung AH, To KW, Chan TO and Yu CM: A prospective cohort study of the long-term effects of CPAP on carotid artery intima-media thickness in obstructive sleep apnea syndrome. Respir Res 13: 22, 2012.

15. Qaseem A, Holty JE, Owens DK, Dallas P, Starkey M and Shekelle P; Clinical Guidelines Committee of the American College of Physicians: Management of obstructive sleep apnea in adults: A clinical practice guideline from the American College of Physicians. Ann Intern Med 159: 471-483, 2013.

16. Niżankowska-Jędrzejczyk A, Almeida FR, Lowe AA, Kania A, Nastałek P, Mejza F, Foley JH, Niżankowska-Mogilnicka E and Undas A: Modulation of inflammatory and hemostatic markers in obstructive sleep apnea patients treated with mandibular advancement splints: A parallel, controlled trial. J Clin Sleep Med 10: 255-262, 2014. 
17. Ursavas A, Karadağ M, Rodoplu E, Yilmaztepe A, Oral HB and Gözü RO: Circulating ICAM-1 and VCAM-1 levels in patients with obstructive sleep apnea syndrome. Respiration 74: 525-532, 2007.

18. Ryan S and McNicholas WT: Inflammatory cardiovascular risk markers in obstructive sleep apnoea syndrome. Cardiovasc Hematol Agents Med Chem 7: 76-81, 2009.

19. Utriainen KT, Airaksinen JK, Polo O, Laitio R, Pietilä MJ, Scheinin H, Vahlberg T, Leino KA, Kentala ES, Jalonen JR, et al: Sleep apnoea is associated with major cardiac events in peripheral arterial disease. Eur Respir J 43: 1652-1660, 2014.

20. Archontogeorgis K, Nena E, Papanas N and Steiropoulos P: Biomarkers to improve diagnosis and monitoring of obstructive sleep apnea syndrome: Current status and future perspectives. Pulm Med 2014: 930535, 2014.

21. Tual-Chalot S, Gagnadoux F, Trzepizur W, Priou P, Andriantsitohaina R and Martinez MC: Circulating microparticles from obstructive sleep apnea syndrome patients induce endothelin-mediated angiogenesis. Biochim Biophys Acta 1842: 202-207, 2014

22. Lin CC, Wang YP, Lee KS, Liaw SF and Chiu CH: Effect of uvulopalatopharyngoplasty on leptin and endothelial function in sleep apnea. Ann Otol Rhinol Laryngol 123: 40-46, 2014

23. Buratti L, Viticchi G, Falsetti L, Cagnetti C, Luzzi S, Bartolini M, Provinciali L and Silvestrini M: Vascular impairment in Alzheimer's disease: The role of obstructive sleep apnea. J Alzheimers Dis 38: 445-453, 2014.

24. Deleanu OC, Malaut AE, Nebunoiu AM, Micheu MM and Mihălţan FD: Obstructive sleep apnea syndrome and arterial hypertension-a complicated relationship? The role of controlling blood pressure values in patients with OSAS. Pneumologia 63: 36-43, 2014.

25. Sasaki N, Ozono R, Yamauchi R, Teramen K, Edahiro Y, Ishii K, Seto A and Kihara Y: The relationship between morning hypertension and sleep quality in patients with obstructive sleep apnea syndrome. Clin Exp Hypertens 35: 250-256, 2013.
26. Alves Eda S, Ackel-D'Elia C, Luz GP, Cunha TC, Carneiro G, Tufik S, Bittencourt LR and de Mello MT: Does physical exercise reduce excessive daytime sleepiness by improving inflammatory profiles in obstructive sleep apnea patients? Sleep Breath 17: 505-510, 2013.

27. Nizam N, Basoglu OK, Tasbakan MS, Nalbantsoy A and Buduneli N: Salivary cytokines and the association between obstructive sleep apnea syndrome and periodontal disease. J Periodontol 85: e251-e258, 2014.

28. Papandreou C: Levels of TBARS are inversely associated with lowest oxygen saturation in obese patients with OSAS. Sleep Breath 17: 1319-1322, 2013.

29. Papandreou C: Independent associations between fatty acids and sleep quality among obese patients with obstructive sleep apnoea syndrome. J Sleep Res 22: 569-572, 2013.

30. Hopps E, Canino B, Calandrino V, Montana M, Lo Presti R and Caimi G: Lipid peroxidation and protein oxidation are related to the severity of OSAS. Eur Rev Med Pharmacol Sci 18: 3773-3778, 2014.

31. Baysal E, Taysi S, Aksoy N, Uyar M, Celenk F, Karatas ZA, Tarakcioglu M, Bilinç H, Mumbuç S and Kanlikama M: Serum paraoxonase, arylesterase activity and oxidative status in patients with obstructive sleep apnea syndrome (OSAS). Eur Rev Med Pharmacol Sci 16: 770-774, 2012.

32. Basoglu OK, Vardar R, Tasbakan MS, Ucar ZZ, Ayik S, Kose T and Bor S: Obstructive sleep apnea syndrome and gastroesophageal reflux disease: The importance of obesity and gender. Sleep Breath 19: 585-592, 2015

33. Pulixi EA, Tobaldini E, Battezzati PM, D'Ingianna P, Borroni V, Fracanzani AL, Maggioni M, Pelusi S, Bulgheroni M, Zuin M, et al: Risk of obstructive sleep apnea with daytime sleepiness is associated with liver damage in non-morbidly obese patients with nonalcoholic fatty liver disease. PLoS One 9: e96349, 2014 